Van Wyk, E. (Compiler). The Talking Dictionary. 2019, 288 pp. ISBN: 9781-920217-74-7. Pretoria: Briza Publications. Price R1250.00. (Additional language sets: R280.00 each.)

The Talking Dictionary hit the market last year in October. It appeared to me that the product was well received by those attending the launch, but is this excitement warranted? In this review, I will explain how the product works, examine its merit and also its usefulness as far as practical application is concerned. I will also speculate as to the possibilities of this product within the context of a classroom. For the purposes of this review, English will be considered the source language and the target language would be any language available from the publisher. Much of what I'm writing about this publication in use is pure speculation, as there is no way to know how it will be received in a classroom situation or even in a home situation at this time.

\title{
How does it work?
}

The Talking Dictionary (hereinafter TTD) includes over 5000 entries and 2000 illustrations which each can be listened to by making use of a call finder, which will be discussed later. The dictionary is organised thematically and none of the entries are organised in alphabetical order. The other aspect that makes this dictionary unique is the fact that there is a section with common phrases and sentences, which you could listen to and read in the target language.

TTD is rather unique and I believe a first on the South African market (the publisher claiming it is one of a kind). While the product is specifically aimed at children (therefore making it a pedagogical dictionary), it may be used for other purposes too, such as basic language acquisition, though this statement is purely speculative.

This dictionary comes with a device called a call finder. The call finder recognises a special pattern printed into the word or illustration, which then enables the reader to find the correct entry in its memory. Similar products have been produced by the publisher of this book, specifically to play bird sounds in field guides.

The device can be loaded with as many language packages as the user intends to purchase. English comes standard with the purchase of the dictionary (call finder included). Additional language packages can be purchased, which include languages like Zulu, Xhosa, Pedi, Tswana and more. A Mandarin language package is in the pipeline, according to the publisher.

One could quite easily plug in a set of headphones into the call finder, making it practically quiet for when a child wishes to use the dictionary on their own, or plug in a set of speakers to play the word to an entire class. 


\section{Not fully electronic and not fully print}

TTD is a strange mix of digital and print. It is neither fully a print dictionary nor an e-dictionary. Early e-dictionaries were simply digitised versions of print dictionaries on floppy disc or CD ROM (Bothma 2011: 72). Since then, many print dictionaries, such as the HAT, VAW and PWN include CDs in the print dictionaries, but many digital dictionaries are only available online (OEDOnline, Wiktionary and Urban Dictionary springing to mind). It would be completely pointless, in my opinion, to have print editions of either Wiktionary or Urban Dictionary, as the users of these products are digital natives. The user perspective therefore, I believe, is "it's online and convenient" because it's fully digital like OEDOnline or many of the dictionaries published by Pharos. These dictionaries are also much more suited to an online environment and the act of browsing than a print dictionary would ever hope to be.

TTD is an odd mix between the two. Yes, you need internet access to load the information onto the call finder, but that is where it ends. You are not bound by internet or at the mercy of bad signal or power cuts, as the call finder works with batteries and stores the entries in its memory. It is meant for children that are essentially digital natives, which may seem bizarre at first glance. One could argue that there are places in South Africa where the 4IR has not yet taken place, never mind the 2nd or 3rd. The media runs stories at the beginning of every school year to show how great the digital divide in the country is and how bad some of the conditions in some schools are, especially in Limpopo and the Eastern Cape. It seems bizarre to try and implement a system such as TTD in this context.

In a way TTD is a happy medium between the two extremes. In a way it gets younger children used to technology and more sophisticated devices, but on the other also exposes them to books, which is still the norm in this country, provided they get delivered.

Print dictionaries are therefore still the standard in South African schools, provided they have access to any kind of lexicographic work. A print dictionary is not dependent on electricity, internet or any device. It is a self-contained unit that children still need to know how to use, should they one day wish to browse a digital dictionary such as the OEDOnline. The OEDOnline has a section where you can browse and uses dictionary typology to do so with a menu listing all the possible words starting with the given n-gram entered into the search bar.

Dictionary skills both for print and digital dictionaries are still useful to have. It may also prove that this product fosters both in time, but that will have to be seen in future.

It clearly resembles picture books very much in the style of "my first words" or "my first dictionary". These publications usually have one word per page in big print, usually on cardboard pages. Slightly more advanced material 
may have more than one illustration per page, but similarly have a rather large print and only one translation equivalent.

It is however a slightly more advanced dictionary, like Collins My First Dictionary (Youtube 2011). This publication however is structured in alphabetical order, even though it does have colourful illustrations and large print. It is also specifically aimed at the age group 5 to 7 , as stated in the video. TTD's intended audience is a bit more fuzzy.

TTD has very small print in comparison to the aforementioned publications (both the picture books and the First Dictionary) because it is clearly intended for older readers (bearing in mind older readers range from about 9+).

Another feature of the dictionary are the sentences and sentence fragments in the final section and the paragraphs introducing the various themes/sections. These can be played over the call finder too, and in theory, one could use the sentence fragments to build sentences with words from other sections.

Because the nature of this dictionary is a bit difficult to determine, it makes it difficult to render a clear opinion. On the one hand, it's great for kids learning new words. On the other, how long will it stay useful before more advanced material is needed? How long until the call finder is replaced with a smart device where you need internet access all the time to work this system, again leaving those who would benefit most from the product in the cold? This situation is definitely one to keep an eye on, as it may cause a bit of a stir.

It is also the only dictionary I've ever come across with an index and every additional language package also has an index. It makes it easier to find a specific word, but it's still not as easy as a traditional dictionary.

\section{Is it any good?}

Using the continuum of the ideal dictionary and ideal user as set out by Gouws and Prinsloo (2005: 42) as a guideline, we can rate this dictionary as having fair to good lexicographic merit (taking into account its purpose and target user) and of course the user would be a user with little to no dictionary skills, since the target user of this dictionary is children. One could only hope that use of this dictionary will eventually lead to the user using more appropriate dictionaries as they age, such as the Oxford Afrikaans-English School Dictionary (OAESD) or the Pharos Junior Bilingual Dictionary (PJBD).

Getting young children interested in dictionaries and dictionary use is of vital importance. TTD can of course be a stepping-stone toward more advanced dictionaries which will match the needs of the user.

The jump from the usage of TTD to, for example, the OAESD is rather vast, as TTD is not organised as a traditional dictionary is. It should however not be an enormous problem, because the organisation of traditional dictionaries already make it more user friendly by giving the lemmas in alphabetical 
order as opposed to category. Of course, the fun of listening to the word as you read it might make a traditional dictionary a bit more boring at first.

Another big difference between the two publications is the fact that the OAESD includes a comment on grammar and comment on semantics with the translation equivalent, and in many cases also gives examples of usage, where TTD only gives the translation equivalent.

It's a pity that the product (as any book in South Africa) is quite expensive. At the time of the launch, the basic package (TTD, the call finder and 1 target language package including a book and download) was R1250. It therefore may not reach those who would benefit the most from it, namely second or third language learners in rural or underprivileged schools. It's fine to argue that you could have a TTD per school or even per class, but would it become yet another thing that you could steal from a school and sell, like computers, TVs or smart boards? Only time will tell.

A pedagogical dictionary, no matter how novel or advanced, is no substitute for a teacher or tutor, who will point out the finer points of usage and grammar where any pedagogical dictionary may fail.

\section{The visual dictionary}

A newer genre of dictionary (at least, one I recently discovered) is the visual dictionary. It seems that TTD fits better into this category (still as a medium between traditional and electronic).

It is stated in TTD that it's based on Le Nouveau Dictionnaire Visuel Junior (NDVJ) by QA International publishing (Van Wyk 2019: 2). This publication is very similar to TTD in many ways, even sharing some of the illustrations, as the publisher bought the copyright to many of the images. One only needs to look at the preview of NDVJ on the website to see many similarities. On the preview of the dictionary (QAI 2020), it is clearly stated that NDVJ is intended for readers 9 and up, which leads me to believe that the target audience for TTD is around 9+ as previously stated.

From what I can gather from the preview, these two publications follow the exact same approach to categorisation and "entries". NDVJ is a bidirectional dictionary, meaning the English translation equivalents are printed in the dictionary itself. It is not a multi-book system with a call finder and looks to be more user friendly.

It seems QAI was at the forefront in providing more visual stimulus to their readers than other publishers.

There are also similar publications online, but those that I could find using Google seem all to be affiliated with QAI.

The "entries" are built around a theme, and possibly even a single image, where multiple words may be present. 


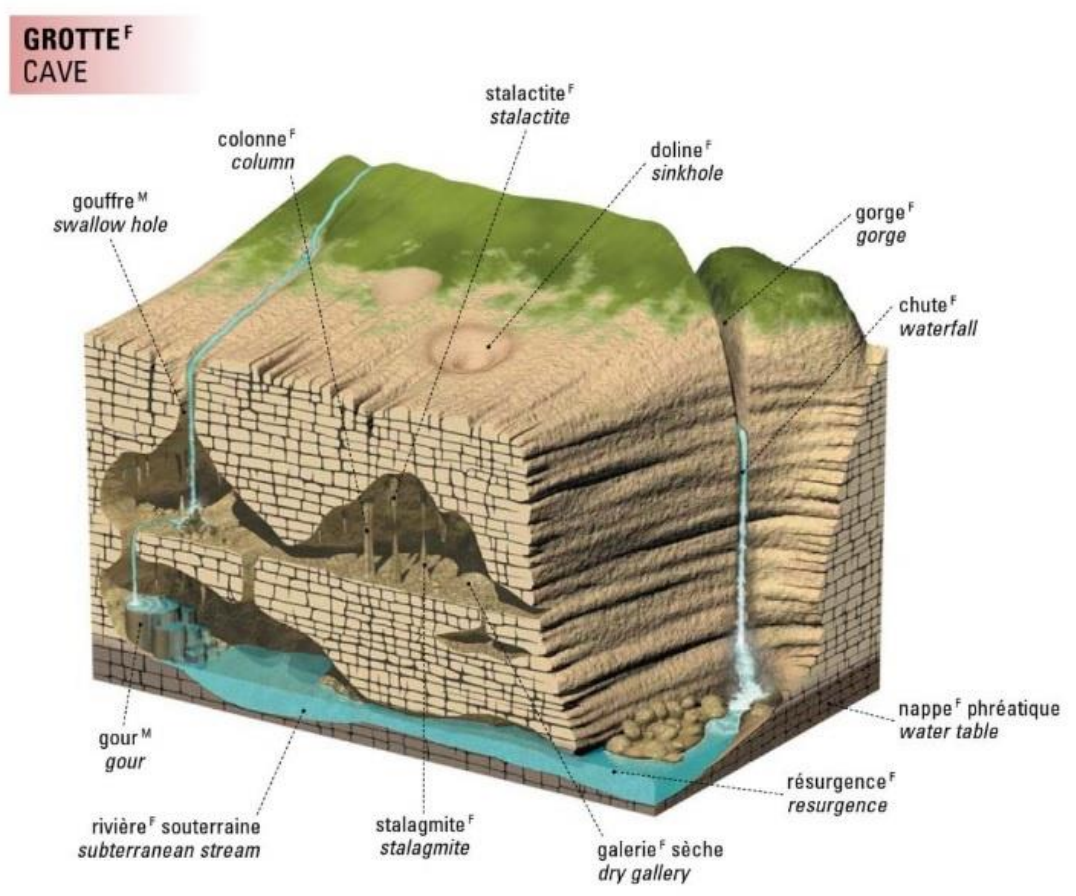

Figure 1: An example of an illustration from NDJV (2003: 30)

It is rather simple to find the word from the image. I am hesitant to use the word "entry", as I will discuss in the next section.

A review of the 2004 edition the NDVJ (as reviews seem hard to find about this publication) was very positive that not only children would benefit from this book (Rufiange 2004: 69). In the review it is indicated that the NDVJ is intended for those 7 and up, which contrasts with the 9+ given in the newer catalogue.

Be that as it may, it gives credence to my thought that it might benefit readers of all ages and levels who may be learning a specific language found in the system. A study using an online visual dictionary seems to support my hypothesis (Osmani 2014: 711).

Research into this format might prove both interesting and fruitful.

\section{The content}

\section{The "entries"}

Most of the words found in the dictionary are nouns, leading me to believe that 
it is somewhat unbalanced. There are basic pronouns and prepositions and very few verbs and adjectives. As far as language acquisition goes, it's very good to expose learners (in this case children) to as many nouns, verbs, adjectives and adverbs as is possible. I do believe that there could be a greater focus on adjectives and basic verbs, so to aid the acquisition of new vocabulary. It may prove difficult to illustrate adverbs in the context of this dictionary where a word is given with little or no context.

The problem however is that some of the nouns found in the dictionary may be a bit too advanced for younger readers - such as specific botanical or mathematical terminologies that would only be of use later in their school career. Many of these terminologies will also be of little or no consequence in a second language or foreign language classroom with young readers. It may however interest older readers who are familiar with those terms or are learning them.

On the other hand, there are terminologies both basic (e.g. parts of the body) and more advanced (e.g. space travel), which might prove useful for school projects and the like in terms of building vocabulary. I must however mention that it is not within the scope of this review to comment on any of the African languages or the Mandarin language packages, as I lack the knowledge to do so. I would think it prudent that linguists and lexicographers specialising in those languages examine the quality of these translation equivalents, but more about that later.

While it is not impossible to illustrate demonstratives in a dictionary, doing so may prove difficult from English to Afrikaans and vice versa solely via an audio recording of the word "this" or "that". "This" and "these" are perfectly acceptable translation equivalents for the Afrikaans words "hierdie" and "dié", which may lead to confusion, should there be little or no guidance given to the user. It may well have been wise to omit demonstratives from the publication. It does however illustrate how problematic it can be where more than one translation equivalent exists and where only one word is given. An example of this problem follows in the next section.

I believe that the pronouns could show more than just the subject form thereof. The possessive forms and object forms of the pronouns could quite easily be given in a table, such as the colours are, but illustrating it may prove difficult, given that it is a printed dictionary.

While a good job was done with prepositions and words denoting position, it could be improved upon in the next edition by adding concepts such as "near", "back", "next to", "far" and other words.

I have purposely not referred to the words in this dictionary as entries, because very often it's just a word accompanying an illustration. No other grammatical or semantic information is given, therefore making the use of the word "entry" questionable. 


\section{The Afrikaans language package}

If we set aside the fact that it's difficult to find specific words owing to the structure of the dictionary and the fact that some of these words may be a bit too advanced for the intended readership, the Afrikaans language package performs rather well. The translation equivalents given are accurate and there are not enormous issues with the package itself. Yes, the adjectives are all given in predicative form, but that is a minor issue which can be solved by a teacher, tutor or grammar. You could in theory build basic Afrikaans sentences by combining the sentences given in the last section with many of the words in the dictionary.

The pronunciation is standard and formal. The words, sentences and paragraphs are all expertly read at a pace that younger users can follow. The problem of course will come in where a native speaker uses this system and there are dialectic differences or some such, which are possible in Afrikaans. It may be an even bigger problem in the African languages or Mandarin.

The system is also a bit clunky because you essentially need two books to do what one bidirectional dictionary can do, but this will be true of all the language packages.

\section{But what about the African and Mandarin language packages?}

The greater problem staring this review in the face, of course, is the fact that I can only review the Afrikaans language package. Afrikaans and Mandarin (which again is only in the planning stage to the best of my knowledge) would be the only two languages that have sufficient lexicographic and digital resources as well as scientific vocabulary for advanced themes, like botanical or paleontological terms (which are both included). A discussion with one of the voice artists who did recordings for the dictionary, leads me to believe that terminologies for the African languages may have been created for this publication. I however lack sufficient knowledge to even make an educated guess as to the accuracy of any of the translation equivalents given in the publication in an African language. I would like to encourage a similar review that focuses on the African languages and the quality of the translation equivalents, given the concerns I have expressed here.

One translation equivalent per word could prove a tricky business when other options are available, such as formal and informal greetings or even adjectives that may need to be declined for concord. In isiXhosa molweni is the greeting which is used for those who are older than you, higher in stature or as a plural, where molo is more informal/familiar. The different options are not given, which might also account for the massive amount of nouns in the publication, which do not necessarily need more than one translation equivalent. A similar problem exists in the Afrikaans language package, where most, if not 
all, adjectives are given in the predicative form, which may confuse learners who encounter the attributive forms in a text. There are words where two possible equivalents are given, but those are few.

Morpho-syntactic issues like these would need to be addressed in language packages where languages, like the Nguni or Sotho sa Leboa languages, are morphologically complex. Again, I am encouraging others to review these language packages as I am no expert on African languages or Mandarin.

\section{Some thoughts}

It is rather difficult to review anything unique. After all, it is not usual to have the sense of hearing engaged to this extent in a print dictionary. One usually needs computer access for that to happen or know how to read IPA transcriptions. It is also quite unusual to have movement of such a nature involved with dictionaries too, which of course also engage kinaesthetic learners more easily.

But given the aim of the dictionary and the price range thereof, it's a nice to have which would be completely out of reach to those who would benefit most from this product: those who do not have access to pronunciation by native or near native speakers in a second language or foreign language classroom.

The big influence this publication may have, is that it may encourage younger dictionary users (from about grade RR age 4 to about grade 3 age 10) to engage with more suitable material later on (grade 4 upwards), such as the OAEDS or even the various bilingual dictionaries offered to that market, such as the PJBD.

To put it simply, TTD is a "nice to have". The quality of the dictionary is commendable and the idea that is being promoted here is quite good. From a purely lexicographic stance, the initiative could be highly praised, provided the African language and Mandarin packages perform as well as the Afrikaans package. However, lexicography is a user driven enterprise and TTD should be evaluated with that in mind.

When I contacted the publisher in January 2020, sales figures did not look good. That may very well be due to the fact that the product was launched last October. Very few children, if any in my opinion, would like a dictionary for Christmas, and money is usually tight in January when new school supplies need to be purchased. A traditional dictionary would then probably be the dictionary of choice to many parents, given the fact that definitions and not just translation equivalents are given in many of these publications (such as OAESD or Pharos).

The use of the call finder could also be a hindrance in the classroom, even when used with earphones. And once again, those who probably would benefit the most from the product, would be left in the cold because of price. 


\section{Conclusion}

I would recommend further inquiry into the potential of this publication. It might be prudent to see how children react to the product and then write another review based on the target market's reception thereof, again working with the frame of user driven lexicography. It is therefore with much turmoil I have to conclude this review with "let's see what happens". It is a concept which is new so we have no other option but to wait and see how it will be received by lexicographers and users alike.

\section{Bibliography}

\section{Dictionaries}

Collins My First Dictionary. See Other literature.

(HAT) Odendal, F.F. and R.H. Gouws (Eds.). 2005, 2011. Handwoordeboek van die Afrikaanse Taal. Pinelands: Pearson Education South Africa.

Louw, P. (Ed.). 2007. Oxford Afrikaans-Engels/English-Afrikaans Skoolwoordeboek/School Dictionary. Cape Town: Oxford University Press Southern Africa.

(NDVJ) Corbeil, J.-C. and A. Archambault. 2003. Le Nouveau Dictionnaire Visuel Junior. Montreal: Quebéc-Amérique International.

OEDonline as accessed on 11 March 2020 https://www.oed.com/Oxford University Press.

(PJBD) Pharos Dictionaries. 2018. Pharos Junior Bilingual Dictionary/Junior Tweetalige Skoolwoordeboek. Cape Town: Pharos.

(PWN) Weijnen, A.A. et al. 1955, 2007. Prisma Woordenboek Nederlands. Utrecht: Het Spectrum.

Urban Dictionary as accessed 12 March 2020 https://www.urbandictionary.com/.

Van Wyk, E. (Compiler). 2011. The Talking Dictionary. Pretoria: Briza Publications.

(VAW) Labuschagne, F.J. and L.C. Eksteen. 1993, 2007. Verklarende Afrikaanse Woordeboek. Pretoria: Van Schaik. Later editions: Cape Town: Pharos

Wiktionary as accessed on 11 March 2020 https://en.wiktionary.org/wiki/Wiktionary:Main_Page.

\section{Other literature}

Bothma, T.J.D. 2011. Filtering and Adapting Data and Information in an Online Environment in Response to User Needs. Fuertes-Olivera. P.A. and H. Bergenholtz. 2011. e-Lexicography: The Internet, Digital Initiatives and Lexicography: 71-102. London/New York: Continuum.

Gouws, R.H. and D.J. Prinsloo. 2005. Principles and Practice of South African Lexicography. Stellenbosch: Sun PReSS.

Osmani, R. 2014. The Effectiveness of Using Technology (Online Visual Dictionary) in Teaching and Acquiring Vocabulary. A Study Conducted at Seeu. The Journal of Teaching English for Specific and Academic Purposes 2(4): 707-713.

QA International Home page 2020 as accessed on 16 March 2020 http://www.qa-international.com/ and Catalogue Preview Page http://www.qa-international.com/docs/CatVisuelJunior.pdf as accessed on 16 March 2020. 
http://lexikos.journals.ac.za; https://doi.org/10.5788/30-1-1574

Rufiange, C. 2004. Review of Le nouveau dictionnaire visuel junior français-anglais. Lurelu 27(2): 68-73. Youtube. 2011. Collins My First Dictionary - Buying Dictionaries for 5-7 Year Olds as accessed on 25 Feb 2020 https://www.youtube.com/watch?v=1rvkkbBvMsE.

Maria Hermione le Roux Department of Afrikaans and Theory of Literature Unisa

Pretoria

South Africa

(lrouxmh@unisa.ac.za) 